\title{
DYNAMIC STABILITY ANALYSIS FOR EGYPTIAN ELECTRICAL GRID WITH THE FIRST NUCLEAR POWER PLANT
}

\author{
Mohamed A. Metwally ${ }^{1}$, Mohamed A. Ali, ${ }^{2}$ Fahmy M. Bendary ${ }^{2}$, Said A. Kutb ${ }^{3}$ \\ and Yassin M. Ibrahem ${ }^{4}$ \\ ${ }^{1}$ Suez Canal Authority \\ ${ }^{2}$ Department of Electrical Engineering, University of Benha \\ ${ }^{3}$ Atomic Energy Authority \\ ${ }^{4}$ Former chairman of N.P.P.A
}

\begin{abstract}
this paper presents the basic dynamic frequency model for the Egyptian electrical grid at 2024. Including five types of energy sources transfer function block diagram models "thermal, hydraulic, gas, nuclear, wind" model, as a one area power system divided on the energy sources shared each one by its ratio. In this paper: a dynamic stability analysis has been makes on this system to study the ability of addition the first Nuclear Power Plant (NPP) to the Egyptian grid. There are two cases of study the frequency disturbance, first one when NPP with different sizes "900 MW \& 1200 MW \& 1400 MW \& $1650 \mathrm{MW"}$ sudden forced outage from the grid, second one when the thermal model loss $1 \%, 2 \%, 5 \%$ and $10 \%$ of power generated. Moreover for treatment this disturbances PID controller has been used to get more system stability and reliability.
\end{abstract}

\section{KEYWORDS:: EGYPTIAN GRID, SIMULINK, TRANSFER FUNCTION, BLOCK DIAGRAM, POWER SYSTEM STABILITY, PID CONTROLLER.}

\section{NOMENCLATURE}

Ksg is Thermal speed governor gain.

RT is Thermal speed regulation of the governor.

Tsg is Thermal speed governor time constant.

$\mathbf{T t}$ is Thermal turbine time constant.

$\mathbf{T r}$ is Thermal re-heater time constant.

$\mathbf{K r}$ is Coefficient of thermal re-heat steam turbine.

TRg is Hydraulic speed governor rest time.

TRH is Hydraulic transient droop time constant.

TGH is Main servo time constant.

Tw is Hydraulic water time constant.

Rhy is Hydraulic speed governor regulation parameter.

$\triangle \mathbf{P C N}$ is Change in speed changer setting of nuclear system.

$\mathbf{R N}$ is Speed regulation of nuclear governor.

TRN is Governor time constant of nuclear system.

T1 is HP nuclear turbine time constant.

$\mathbf{K H}$ is Coefficient of HP re-heat nuclear steam turbine.

KR is Coefficient of LP re-heat nuclear steam turbine.

TRH is LP nuclear turbine time constant.

$\mathbf{X}$ and $\mathbf{Y}$ are Gas speed governor lead and lag time constants.

$\mathbf{a}, \mathbf{b}$ and $\mathbf{c}$ are Gas valve positioner constants.

TF is Gas fuel time constant.

TCR is Gas combustion reaction time delay.

TCD is Gas compressor discharge volume time constant.

$\mathbf{R g}$ is Gas speed governor regulation parameter.

$\mathbf{K g w}$ is Wind speed governor gain. 
Tgw is Wind speed governor time constant.

Ttw is Wind turbine time constant.

$\mathbf{K g w}$ is Wind turbine gain.

$\mathbf{R}_{\mathbf{w}}$ is Wind governor speed regulation.

Fr is Nominal system frequency.

Pr is Rated power of the system "MW".

$\boldsymbol{\Delta} \boldsymbol{\delta}$ is change in power angle.

$\Delta \mathbf{P m}$ is Change in mechanical power.

$\Delta \mathbf{P e}$ is Change in electrical power.

$\mathbf{H}$ is inertia constant of the generator "MW-s/MVA" .

D is System damping "load frequency characteristic" pu MW/Hz.

$\mathbf{K} \mathbf{p s}$ is Power system gain $=1 / \mathrm{D} \mathrm{Hz} / \mathrm{pu} \mathrm{MW}$.

Tps is Power system time constant $=2 \mathrm{H} /(\mathrm{Fr} * \mathrm{D})$ sec.

\section{INTRODUCTION}

Large scale power systems are normally composed of control areas or regions representing coherent groups of generators. In a future combination of electricity in Egypt, the generation normally comprises of a mix of thermal, hydro, nuclear, gas and wind or renewable power generation. However, owing to their high efficiency, nuclear plants are usually kept at base load close to their maximum output with no participation in the system Automatic Generation Control (AGC). Gas power generation is ideal for meeting the varying load demand. Gas plants are used to meet peak demands only. Thus the natural choice for AGC falls on either thermal or hydro units [1, 2, 3 and 4$]$.

Since the time of construction of the nuclear plant takes from six to seven years, so this was a study on 2024. According to the latest load forecast research results in Egypt for year 2024 is approximately 60 GW, were in line with expectations with loads of of the company's Egyptian electricity holding the Egyptian ministry of electricity [5,6]. This paper study the system performance of Egyptian grid at 2024 by tracking the change in system frequency values for each case mentioned above, and try to maintain the difference in the change within a reasonable values by adding PID controller. Simulink tool in MATLAP program has been used for simulate the Egyptian electrical grid model as a transfer function block diagram [7].

\section{EGYPTIAN ELECTRICAL GRID DATA}

Before the start in our study there important information about Egypt's current electrical grid and future expectations for the electrical grid in 2024 must be present and are as follows.

\subsection{A current combination of the Egyptian electrical grid}

After reviewing the annual report for the year 2014 of the company's Egyptian Electricity Holding the Egyptian Ministry of Electricity show that the total production of electricity in Egypt for the year 2014 is almost $30 \mathrm{GW}$ and the current combination of the sources of electricity production in Egypt as follows in Tab. 1[5].

Tab. 1: A current combination of the Egyptian electrical grid

\begin{tabular}{|c|c|c|}
\hline $\begin{array}{c}\text { Source } \\
\text { type }\end{array}$ & $\begin{array}{c}\text { Total } \\
\text { production in GW }\end{array}$ & $\begin{array}{c}\text { Total } \\
\text { production in \% }\end{array}$ \\
\hline Thermal & $20 \mathrm{GW}$ & $60 \%$ \\
\hline Gas & $7.5 \mathrm{GW}$ & $27 \%$ \\
\hline Hydraulic & $2.8 \mathrm{GW}$ & $10 \%$ \\
\hline $\begin{array}{c}\text { Wind and } \\
\text { Renewable }\end{array}$ & $1 \mathrm{GW}$ & $3 \%$ \\
\hline
\end{tabular}

\subsection{The proposed combination of the Egyptian electricity grid at 2024}

After study the current combination of the Egyptian grid, also review the future plans of the Ministry of Electricity in the construction of various types of plants for the production of electrical energy over the next ten year, and also predicted the total loads of the Egyptian grid in 2024 where it was almost $60 \mathrm{GW}$ [6].

Taking into account all the circumstances and requirements for the production of electrical energy in 2024 from the fuel sources and construction time of a new different types of power plants, it has been found an urgent need to start building the first nuclear power plant in Egypt to overcome the increasing in the loads 
and decreasing in the fuel sources. Knowing that the construction of this station time about seven years, so our simulation must have been make at 2024.

So the chart of the Egyptian electrical grid will be changed to become at 2024 as shown in Tab. 2.

Tab. 2: The proposed combination of the Egyptian electrical grid at 2024

\begin{tabular}{|c|c|c|}
\hline Source type & $\begin{array}{c}\text { Total production } \\
\text { in GW }\end{array}$ & $\begin{array}{c}\text { Total production in } \\
\text { \% }\end{array}$ \\
\hline Thermal & $33 \mathrm{GW}$ & $55 \%$ \\
\hline Gas & $18 \mathrm{GW}$ & $30 \%$ \\
\hline Hydraulic & $3.2 \mathrm{GW}$ & $6 \%$ \\
\hline Nuclear & $0.9: 1.65 \mathrm{GW}$ & $1.5: 2.8 \%$ \\
\hline $\begin{array}{c}\text { Wind and } \\
\text { Renewable }\end{array}$ & $4.5: 3.75 \mathrm{GW}$ & $7.5: 6.2 \%$ \\
\hline
\end{tabular}

\section{MODELING OF POWER SYSTEM}

Action will be design of the Egyptian electrical grid in year 2024 in the form of transfer function block diagrams as a one area power system, Electricity produced divided in the Tab.2 proportions indicated in the table and illustrated in Fig.1 [8].

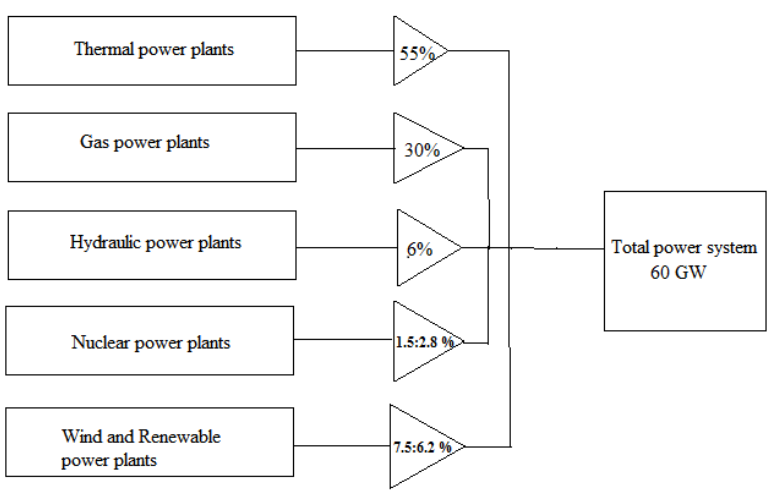

\section{1 thermal model}

Fig.1.The proposed combination of the Egyptian electrical grid at 2024

A single area thermal power system has two main parts that are speed governor and turbine. In starting it is assumed that this system is linear for simplicity. The transfer function block diagram model of thermal governor is shown as in Fig. 2 [7] [9].

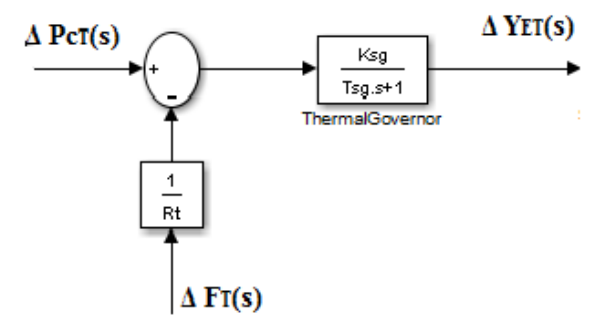

Fig.2.Thermal Power Plant Speed Governor Model

The turbine transfer function is characterized by two time constants. For ease of analysis, it will be assumed here that turbine can be modelled to have a single equivalent time constant. Fig. 4.7 and 4.8 shows the transfer function model of a steam turbine without reheat and with reheat unit respectively. Typically the time constant $\mathrm{T} 1$ lies in the range 0.2-2.5 $\mathrm{s}$ as shown in Fig. 3 [7] [9]. 


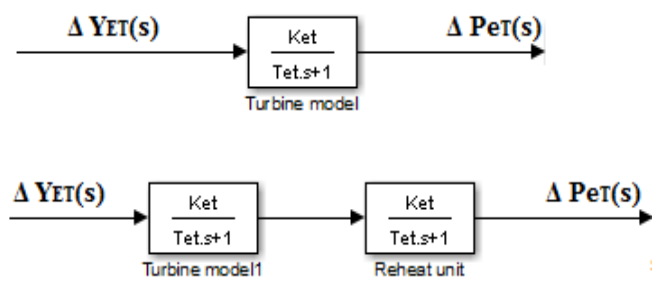

Fig.3.Thermal power plant steam turbine model

\subsection{Hydraulic model}

As for the requirement of hydro-electric power system modeling for load frequency control, speed governor and turbine should be modeled. The model development of different components of single area hydro system is explained as in Fig. $4[10,11]$.

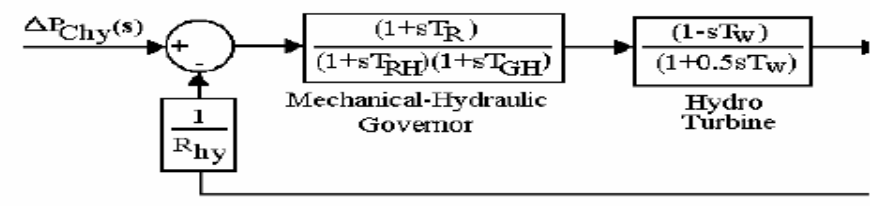

Fig.4.Transfer function block diagram of a hydraulic power plant

\subsection{Gas model}

As for the requirement of gas power system modeling for load frequency control, speed governor, valve positioner, fuel system and turbine should be modeled. These are modelled as shown in Fig. $5[12,13]:$

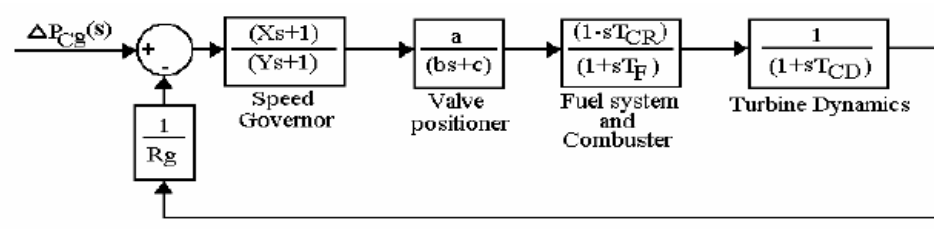

Fig.5.Transfer function block diagram of a gas power plant

\subsection{Nuclear model}

As for the requirement of nuclear power system modelling for load frequency control, speed governor and turbine should be modelled. The transfer function block diagram model of governor is shown as in Fig. 6 [11]:

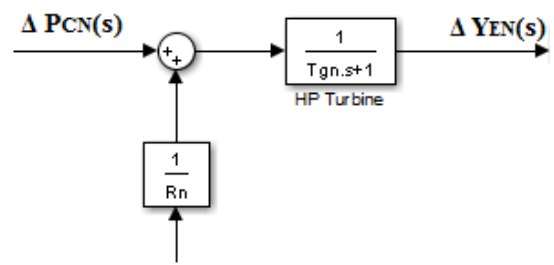

Fig.6.Nuclear Power Plant Speed Governor Model.

The Mathematical model considered for nuclear unit tandem-compound turbines, one HP section and two LP section with HP reheater as shown in Fig. 4.14. The HP exhausts Moisture Separator Reheater (MSR) before entering the LP turbine. The MSR reduces the moisture content of the steam entering the LP section, thereby reducing the moisture and erosion rates. High pressure steam is used to reheat the HP exhaust as show in Fig. 7: 


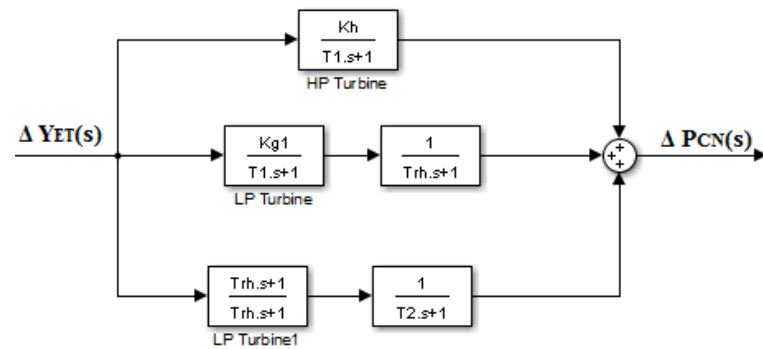

\subsection{Wind model}

Fig.7.Nuclear power plant turbine model

As for the requirement of wind power system modelling for load frequency control, speed governor, and turbine should be modelled. These are modelled as shown in Fig. 8 [14, 15]:

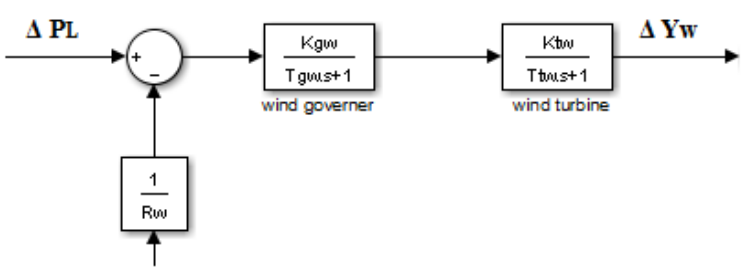

Fig. 8. Transfer function block diagram of a wind power plant

\subsection{Load and generator model}

The generator dynamics is modelled by swing equation and given in equation no.1:

$$
\frac{2 H}{w_{s}} \frac{d^{2} \Delta \delta}{d t^{2}}=\Delta P m-\Delta P e
$$

For small perturbation the above relation can be represented by a block diagram as shown in Fig. 9 [7]:
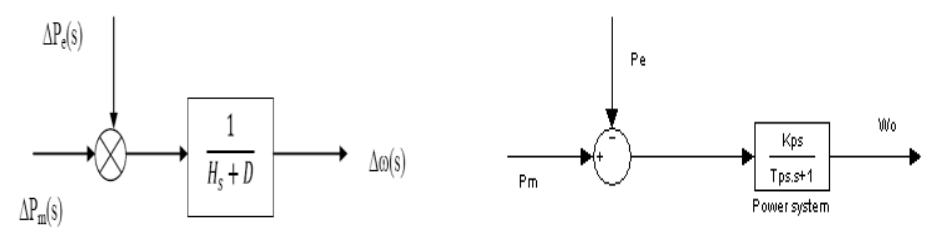

Fig.9.Transfer function block diagram of generator and load "power system".

The dynamic performance of Load Frequency Control (LFC) has been made based upon a linearized analysis. The simple LFC model does not consider the effects of the physical constraints. Although considering all dynamics in frequency control synthesis and analysis may be difficult and not useful, it should be noted that to get an accurate perception of the LFC subject it is necessary to consider the important inherent requirement and the basic constraints imposed by the physical system dynamics, and model them for the sake of performance evaluation [7].

\section{THE BLOCK DIAGRAM MODEL FOR THE EGYPTIAN ELECTRICAL GRID AT 2024}

From the previous study of the different types of energy sources to produce the electricity and how to simulate in a transfer function block diagram models, now we can put an initial vision or suppose block diagram model for the Egyptian electrical grid at 2024.

To apply this model will be collected the Productive capacity of electricity from the same type of power plants in one equivalent block diagram multiplied by the percentage of the total value of the electricity produced [16] as shown in Fig. 10.

Where,

$\mathrm{Fr}=50 \mathrm{~Hz}, \operatorname{Pr}=60000 \mathrm{MW}, \mathrm{H}=5 \mathrm{MW}-\mathrm{s} / \mathrm{MVA}$. 


\section{CASE STUDIES ON THE OUR MODEL}

To complete study the dynamic stability and reliability on the system after adding the first NPP to the Egyptian grid, two cases of study have been illustrated in the next section.

\subsection{NPP with different sizes sudden forced outage from the grid}

To assure that the grid on the province the system stability after adding the first NPP, must be select the optimum size of the NPP from the available sizes around the world "900 MW \& 1200 MW \& 1400 MW \& 1650 MW". Study the stability of our model with each one after sudden outage them from the grid by using switch tool in Simulink as shown in Fig. 10.

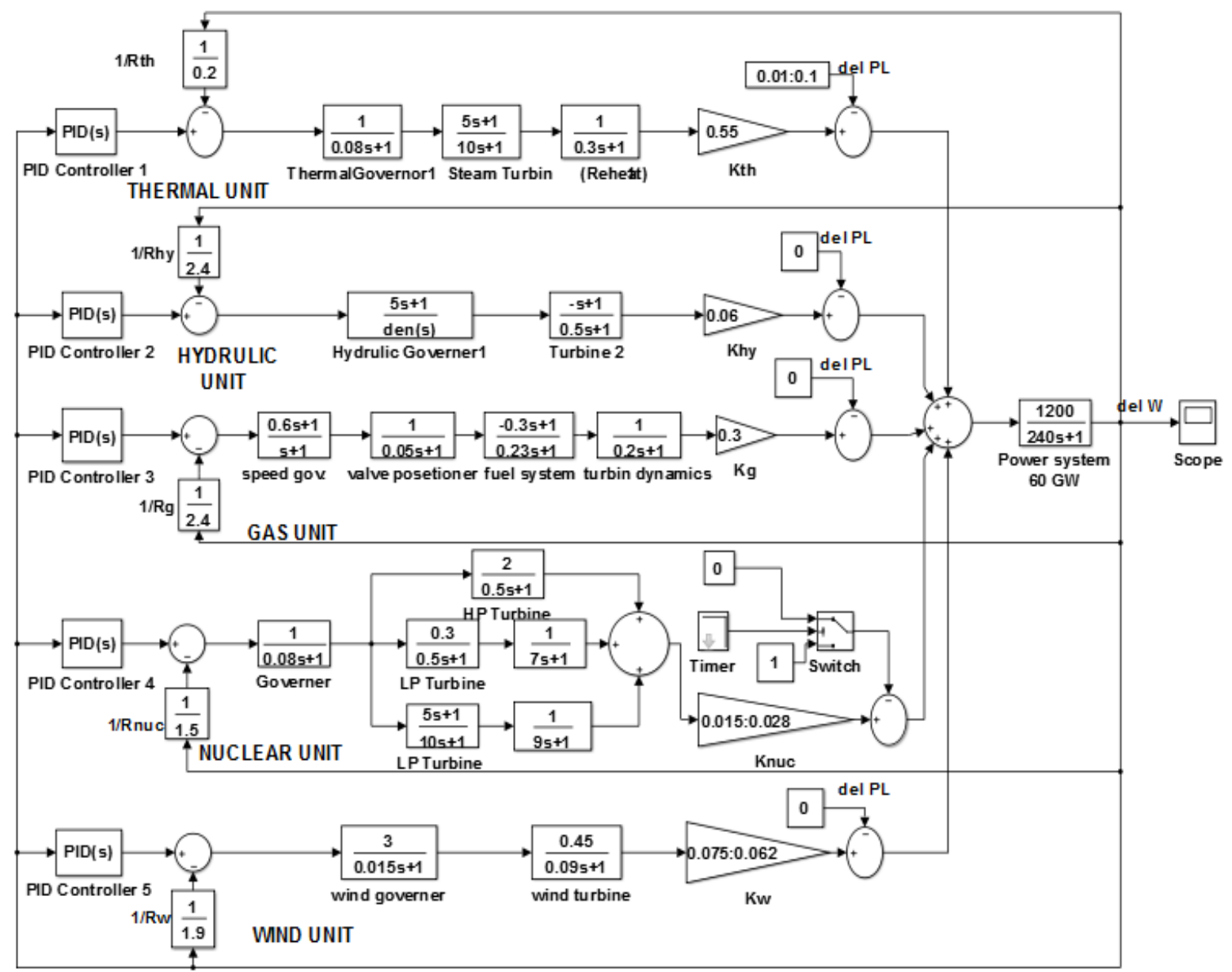

Fig.10. transfer function block diagram for Egyptian electrical grid at 2024

\section{2 when the thermal model loss $1 \%, 2 \%, 5 \%$ and $10 \%$ of power generated}

To do sensitivity analysis or study the effect of varying various parameters on the dynamic responses of the Egyptian electrical grid, $1 \%, 2 \%, 5 \%$ and $10 \%$ step load perturbation in the thermal model has been done as shown in Fig 10. PID controller has been added to the system in the two cases to overcome the effect of this disturbance, and the change in the system frequency will be seen in the results section before and after PID controller.

\section{Simulation and results}

The PID controller will be used for the stabilization of the frequency in the AGC problems. So tuning of PID controller is very important to get optimal performance.

PID controller consists of Proportional, Integral and Derivative actions. It is usually tuned by Ziegler-Nichols method. Ziegler-Nichols method is by far the most common control algorithm [17]. In this paper we propose 
a simple method for tuning of PID controller through MATLAB Simulink. The proposed methodology is implemented for AGC power system [18, 19 and 20].

\subsection{The NPP suddenly outage from Egyptian grid model}

After five second switch tool in Simulink has been used for forced outage the NPP with four sizes "900 MW \& $1200 \mathrm{MW} \& 1400 \mathrm{MW} \& 1650 \mathrm{MW}$ " from the model, the frequency response for the system with the four sizes of NPP the same which appear on the scope shown in Fig. 11, where the maximum change in frequency delta $\mathrm{F}$ reaches to $" \Delta \mathrm{F}=\underline{-1.7 "}$ i.e. about $\underline{80 \mathrm{~Hz}}$, and the curve don't return to zero again its mean system not stable and out of control.

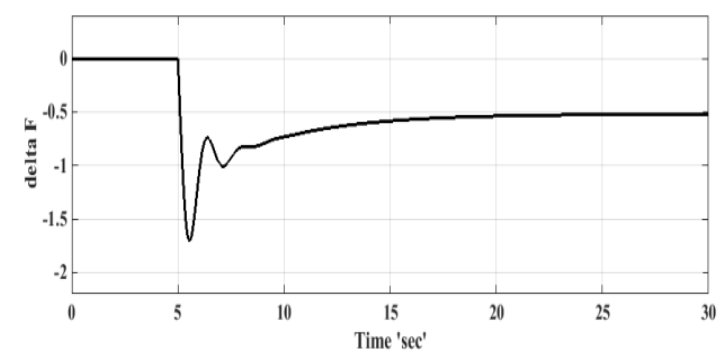

Fig.11.The change in frequency when the NPP outage

Five PID controllers have been added to the system with values seen in tab. 3, to overcome the effect of this disturbance, and the change in the system frequency will be seen in Fig. 5.12.

Tab.3. PID controller's parameters values

\begin{tabular}{|l|l|l|l|l|l|l|l|l|l|l|l|l|l|l|}
\hline \multicolumn{3}{|c|}{ PID (1) } & \multicolumn{3}{c|}{ PID (2) } & \multicolumn{3}{c|}{ PID (3) } & \multicolumn{3}{c|}{ PID (5) } \\
\hline Kp1 & Ki1 & Kd1 & Kp2 & Ki2 & Kd2 & Kp3 & Ki3 & Kd3 & Kp4 & Ki4 & Kd4 & Kp5 & Ki5 & Kd5 \\
\hline-350 & -100 & -100 & 5000 & 1200 & 7000 & -40 & -44 & -40 & -50 & -60 & -70 & -20 & -640 & -40 \\
\hline
\end{tabular}

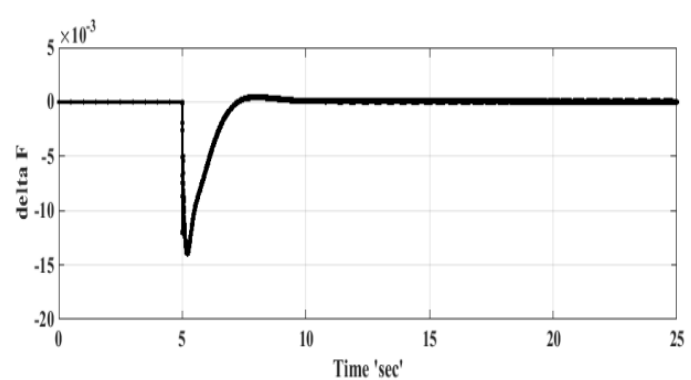

Fig.12.The change in frequency when the NPP outage

The maximum change in frequency delta $\mathrm{F}$ reaches to " $\Delta \mathrm{F}=\underline{-0.014 "}$ i.e. about $\underline{0.7 \mathrm{~Hz}}$, and the curve returned to zero again its mean system become stable, this for the four sizes of NPP.

\subsubsection{The frequency response for $1 \%$ load perturbation}

After $1 \%$ load perturbation happen on the thermal unit in our model the frequency response Shown in Fig. 13, where the maximum change in frequency delta $\mathrm{F}$ reaches to $" \Delta \mathrm{F}=\underline{-0.017 "}$ i.e. about $\underline{0.85 \mathrm{~Hz}}$, and the curve don't return to zero again its mean system not stable. PID controller has been added on the thermal branch to the system with parameters values $\mathrm{Kp}=-9 \& \mathrm{Ki}=-9 \& \mathrm{Kd}=-3$, to overcome the effect of this disturbance, and the change in the system frequency will be seen in Fig. 13.

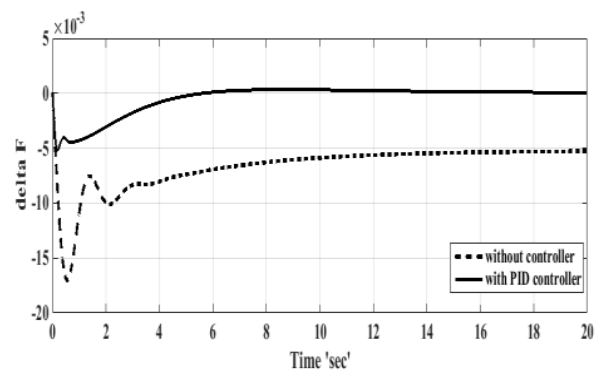

Fig.13.The frequency response when $1 \%$ thermal unit loss 
When adding the PID controller the maximum change in frequency delta $\mathrm{F}$ reaches to " $\Delta \mathrm{F}=\underline{-0.005 " \text { i.e. about }}$ $\underline{0.25 \mathrm{~Hz}}$, and the curve returned to zero again its mean system become stable.

\subsubsection{The frequency response for $2 \%$ load perturbation}

After $2 \%$ load perturbation happen on the thermal unit in our model the frequency response Shown in Fig. 14 , where the maximum change in frequency delta $F$ reaches to $" \Delta F=-0.034 "$ i.e. about $1.7 \mathrm{~Hz}$, and the curve don't return to zero again its mean system not stable. PID controller has been added on the thermal branch to the system with parameters values $\mathrm{Kp}=-10 \& \mathrm{Ki}=-9 \& \mathrm{Kd}=-5$, to overcome the effect of this disturbance, and the change in the system frequency will be seen in Fig. 14.

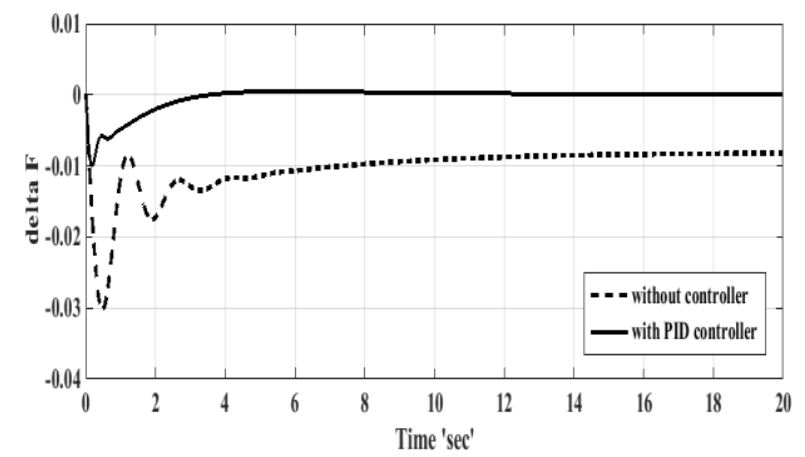

Fig.14. the frequency response when $2 \%$ thermal unit loss

The maximum change in frequency delta $\mathrm{F}$ reaches to $" \Delta \mathrm{F}=\underline{-0.01 "}$ i.e. about $\underline{0.5 \mathrm{~Hz}}$, and the curve returned to zero again its mean system become stable.

\subsubsection{The frequency response for $5 \%$ load perturbation}

After $5 \%$ load perturbation happen on the thermal unit in our model the frequency response Shown in Fig.

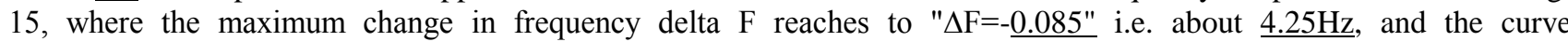
don't return to zero again its mean system not stable. PID controller has been added on the thermal branch to the system with parameters values $\mathrm{Kp}=-11 \& \mathrm{Ki}=-10 \& \mathrm{Kd}=-7$, to overcome the effect of this disturbance, and the change in the system frequency will be seen in Fig. 15.

The maximum change in frequency delta $\mathrm{F}$ reaches to " $\Delta \mathrm{F}=-0.016$ " i.e. about $0.8 \mathrm{~Hz}$, and the curve returned to zero again its mean system become stable.

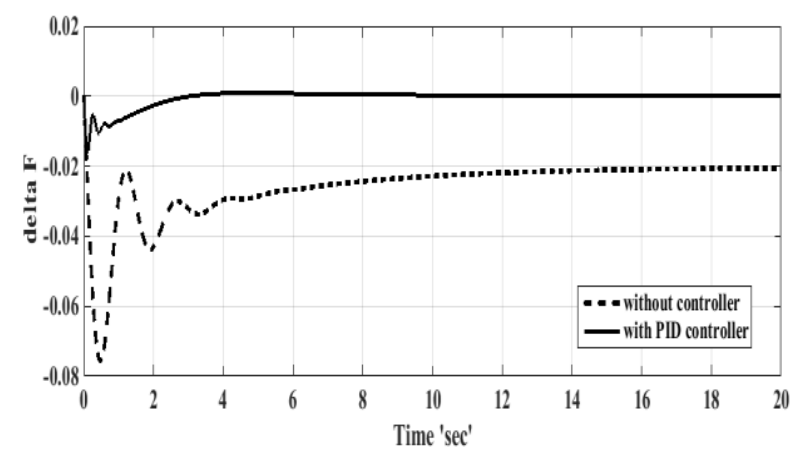

Fig.15.The frequency response when $5 \%$ thermal unit loss

\subsubsection{The frequency response for $10 \%$ load perturbation:}

After $10 \%$ load perturbation happen on the thermal unit in our model the frequency response Shown in Fig. 16 , where the maximum change in frequency delta $\mathrm{F}$ reaches to $" \Delta \mathrm{F}=-0.17$ " i.e. about $8.5 \mathrm{~Hz}$, and the curve don't return to zero again its mean system not stable. PID controller has been added on the thermal branch to the system with values $\mathrm{Kp}=-10 \& \mathrm{Ki}=-10 \& \mathrm{Kd}=-10$, to overcome the effect of this disturbance, and the change in the system frequency will be seen in Fig. 16.

The maximum change in frequency delta $\mathrm{F}$ reaches to $" \Delta \mathrm{F}=\underline{-0.025}$ " i.e. about $\underline{1.25} \mathrm{~Hz}$, and the curve returned to zero again its mean system become stable. 


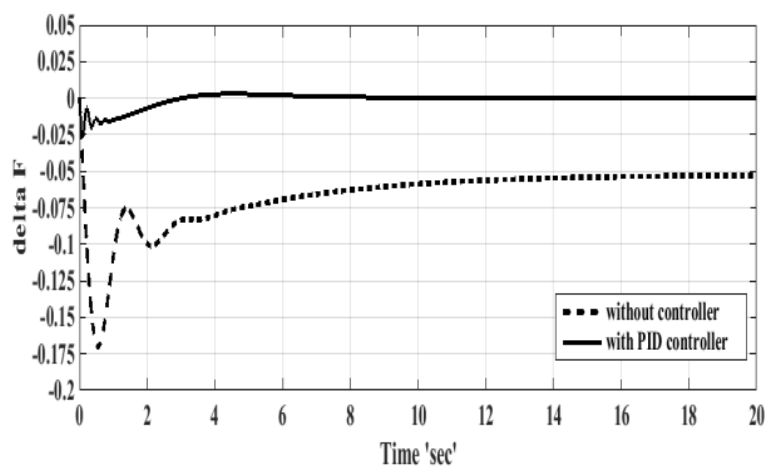

Fig.16. the frequency response when $10 \%$ thermal unit loss

\section{CONCLUSION}

After finishing the dynamic stability study on the primly Egyptian electrical grid, it's clear that:

First, all sizes of NPPs "900 MW \& 1200 MW \& 1400 MW \& 1650 MW" can be used as a first NPP added to Egyptian grid, where that can be controlling on the frequency response when the NPP outage from the grid by using PID controlling. Which the maximum $\Delta \mathrm{F}=\underline{-0.014}$ i.e. about $\underline{0.7 \mathrm{~Hz}}$, and the system return to zero in four seconds.

Second, our model exposure to a load perturbation up to $10 \%$ on the thermal units, the maximum " $\Delta \mathrm{F}=$ $0.025 "$ i.e. about $1.25 \mathrm{~Hz}$ the curve returned to zero again after three second by using PID controller, These mean the system is stable.

\section{References}

1. Kundur P. 1994. Power system stability and control. New York: McGraw-Hill.

2. Naimul Hasan, Ibraheem, Shuaib Farooq, "Real Time Simulation of Automatic Generation Control for Interconnected Power System", International Journal on Electrical Engineering and Informatics, March 2012

3. Yao Zhang," Load Frequency Control of Multiple-Area Power Systems", M.Sc., Cleveland State University, 2009.

4. Goran Andersson, "Dynamics and Control of Electric Power Systems", EEH - Power Systems Laboratory, ETH Zurich university, 2012.

5. Annual Report 2013/2014 Ministry of Electricity and Energy, Egypt.

6. Mohamed A. Metwally, " Long-term Forecasting for Total Electricity Demand in Egypt Using ANFIS Predictor", sixteen international middle east power system conference (MEPCON'14), Ainshams university, 2014.

7. Hadi Saadat, "Power System Analysis".

8. Yassin M. Ibrahim, "Study of nuclear power station addition to A.R.E network", M.SC. Faculty of engineering Cairo University, 1977.

9. Aditi Gupta, " Sensitivity Analysis of Multi-Area Hybrid Power System Integrated with Integral Controllers" International Journal of Advanced Research in Computer Science and Software Engineering, 2013.

10. Surya Prakash, A. K. Bhardwaj, "Neuro Fuzzy Hybrid Intelligent Approach for Four -Area Load Frequency Control of Interconnected Power System", International Conference on Power, Control and Embedded Systems, 2012.

11. Mohit Kumar Pandey and Mohit Kumar Pandey, "Load frequency Control of Hydro and Nuclear Power System by PI \& GA Controller", International Journal of Scientific Research Engineering \& Technology (IJSRET), September 2013.

12. C.Srinivasa Rao, "Load Frequency Control of Multi Area Interconnected System with Tcps and Diverse Sources of Power Generation", Global Institute for Research and Education, December, 2013.

13. K. P. Singh Parmar, S. Majhi, "LFC of an Interconnected Power System with Thyristor Controlled Phase Shifter in the Tie Line", International Journal of Computer Applications, 2012.

14. N. Kiran Kumar, I.E.S. Naidu,"Load Frequency Control for A Multi Area Power System Involving Wind, Hydro and Thermal plants", International Journal of Innovative Research in Science, Engineering and Technology (IJIRSET), 2014. 
15. K. Harinadha Reddy, "Study and Analysis of LFC with Wind Plant in Two Area Power System through Fuzzy Inference Technique", International Journal of Innovative Technology and Exploring Engineering (IJITEE), 2014.

16. K. S. S. Ramakrishna, Pawan Sharma, "Automatic generation control of interconnected power system with diverse sources of power generation", International Journal of Engineering, Science and Technology, 2010..

17. K.J. Astrom, T. Hagglund, "Revisiting the Ziegler-Nichols step response method for PID control", science direct, Journal of Process Control 14 (2004).

18. G. Konar, K. K. Mandal, and N. Chakraborty, "Two Area Load Frequency Control Using GA Tuned PID Controller in Deregulated Environment", Proceedings of the International MultiConference of Engineers and Computer Scientists, 2014.

19. Shasya Shukla, Fatima Yasmeen, " Controlling the Active Power and Frequency of Single and Multi Area Interconnected Power System Using PID Controller", International Journal of Engineering Research and General Science, 2015.

20. M Nagendra, M.S.Krishnarayalu, "PID Controller Tuning using Simulink for Multi Area Power Systems", International Journal of Engineering Research \& Technology (IJERT), 2012. 